\title{
Author Correction: CDK2-mediated site-specific phosphorylation of EZH2 drives and maintains triple-negative breast cancer
}

Lei Nie, Yongkun Wei, Fei Zhang, Yi-Hsin Hsu, Li-Chuan Chan, Weiya Xia, Baozhen Ke, Cihui Zhu, Rong Deng, Jun Tang, Jun Yao, Yu-Yi Chu, Xixi Zhao, Ye Han, Junwei Hou, Longfei Huo, How-Wen Ko, Wan-Chi Lin, Hirohito Yamaguchi, Jung-Mao Hsu, Yi Yang, Dean N. Pan (D, Jennifer L. Hsu, Celina G. Kleer, Nancy E. Davidson, Gabriel N. Hortobagyi \& Mien-Chie Hung

Correction to: Nature Communications https://doi.org/10.1038/s41467-019-13105-5, published online 8 November 2019.

The original version of this Article omitted the following funding source from the Acknowledgements:

CPRIT Research Training Program (RP101502, 140106, and 170067; to H.-W.K.). This has been corrected in the PDF and HTML versions of the Article.

Published online: 29 January 2020

(c) (1) Open Access This article is licensed under a Creative Commons Attribution 4.0 International License, which permits use, sharing, adaptation, distribution and reproduction in any medium or format, as long as you give appropriate credit to the original author(s) and the source, provide a link to the Creative Commons license, and indicate if changes were made. The images or other third party material in this article are included in the article's Creative Commons license, unless indicated otherwise in a credit line to the material. If material is not included in the article's Creative Commons license and your intended use is not permitted by statutory regulation or exceeds the permitted use, you will need to obtain permission directly from the copyright holder. To view a copy of this license, visit http://creativecommons.org/licenses/by/4.0/.

(c) The Author(s) 2020 